\title{
To what extent should the Convention of Cabinet Secrecy still be recognised in South African constitutional law?
}

\section{Introduction}

This note deals with the question whether, under the present-day South African constitutional law, members of the public are entitled to any information held by cabinet (the national executive). This question is considered with specific reference to the law of comparative jurisdictions. Two competing principles must be considered: on the one hand, the constitutional right of access to information held by the state (cabinet information in the present case) and, on the other hand, the convention of cabinet secrecy. The latter originated in English constitutional law, which might be argued to have been inherited by South Africa.

The note will first deal with the relevant provisions in the Constitution of the Republic of South Africa of 1996 (hereafter the Constitution), the Promotion of Access to Information Act 2 of 2000, and applicable dicta from South African case law. The law of selected comparable jurisdictions which are sufficiently similar to that of South Africa will then be discussed. Such foreign law would be the most instructive for the local legal position and thus capable of reaching a motivated conclusion on the matter under discussion. The jurisdictions selected for comparative analysis are those of England (and Whales), Canada, Australia, India and Kenya.

\section{The Position in South Africa}

Section 32 of the Constitution provides, with regard to the constitutional right of access to information, that:

(1) Everyone has the right of access to -

(a) any information held by the state; and

(b) any information that is held by another person and that is required for the exercise or

protection of any rights.

How to cite: Malan 'To what extent should the Convention of Cabinet Secrecy still be recognised in South African constitutional law?' 2016 De Jure 117-133

http://dx.doi.org/10.17159/2225-7160/2016/v49n1a8 
(2) National legislation must be enacted to give effect to this right, and may provide for reasonable measures to alleviate the administrative and financial burden on the state.

The founding values of the South African Constitution, outlined in section 1 , are arguably also pertinent in dealing with the issue of access to information. Section 1 provides as follows (own emphasis):

The Republic of South Africa is one, sovereign, democratic state founded on the following values:

(a) Human dignity, the achievement of equality and the advancement of human rights and freedoms.

(b) Non-racialism and non-sexism.

(c) Supremacy of the constitution and the rule of law.

(d) Universal adult suffrage, a national common voters roll, regular elections and a multi-party system of

democratic government, to ensure accountability, responsiveness and openness.

It should be clear from the emphasised part of section 1 that the raison d'etre of the values is to ensure accountability, responsiveness and openness. Hence, the values set out in section 1(a), like the values mentioned in the other subsections, are intended to achieve an objective, namely, to ensure accountability, responsiveness and openness (transparency).

In spite of the fact that the section 1 values are not justiciable (Minister of Home Affairs v NICRO 2004 (5) BCLR 445 (CC) 455D-E par 21), they fulfil a significant function in litigation, namely, as an important aid to interpretation and a basic legal source of last resort. Therefore, whenever a provision is open to more than one interpretation, the interpretation that best advances the achievement of accountability, responsiveness and openness should be preferred. This is particularly pertinent for the present issue dealing with access to information held by the state (cabinet in the present discussion): a context in which the achievement of accountability, responsiveness and openness is patently relevant.

Thus, in Minister of Home Affairs $v$ NICRO (supra at 455 D-E par 21) the Constitutional Court stated as follows:

The values enunciated in $\mathrm{s} 1$ of the Constitution are of fundamental importance. They inform and give substance to all the provisions of the Constitution. They do not, however, give rise to discrete and enforceable rights in themselves. This is clear not only from the language of s 1 itself, but also from the way the Constitution is structured and in particular the provisions of Chapter 2 which contains the Bill of Rights.

The same sentiment was voiced in Chirwa $v$ Transnet Ltd (2008 (4) SA 367 (CC) par 74).

The legislation that was passed in order to give effect to section 32(2) of the Constitution is the Promotion of Access to Information Act 2 of 
2000 (hereafter PAIA). PAIA provides for a sweeping right of access to information held by public bodies (s 11). This Act, however, does not apply to a record of the proceedings of cabinet or its committees (s 12(a) of PAIA).

This lacuna has two implications. First, section 32 of the Constitution, and not PAIA, is the law which is applicable to the present issue. Second, whenever a public body, including cabinet, denies access to information it would constitute a prima facie infringement of the constitutional right of access to information. Such infringement would be justified only in terms of a law of general application (in accordance with s 36 of the Constitution) but with the exclusion of any of the exceptions provided for in PAIA, more particularly in Chapter 5 (ss 33-46). If the respondent (cabinet) would deny access, therefore prima facie infringing the right of access to information, it bears the onus of showing that the requirements for the justification of such denial, as set out in section 36(1) of the Constitution, have been met (Ferreira v Levin NO 1996 (1) SA 984 (CC) par 44).

Such refusal to disclose cabinet information may be justified in terms of the convention of cabinet secrecy (privilege/confidentiality), which is arguably a law of general application as envisaged in section 36(1) of the Constitution (in this regard, see the argumentation of Mokgoro $\mathrm{J}$ in President of the Republic of South Africa v Hugo 1997 (6) BCLR 708 (CC) par 99). The convention originated in the Westminster constitutional order as practised in the United Kingdom (UK) and has been transplanted into other common law jurisdictions that follow the Westminster model.

The basis of the convention of cabinet secrecy is the principle of the collective accountability of the national executive (cabinet) to the national legislature (and to the public). In terms of this principle, all members of cabinet assume collective responsibility for the policies adopted by cabinet, thus preventing an individual member from distancing himself/herself from a decision on the grounds that he/she is not in agreement with it and has expressed such disagreement during cabinet deliberations. In this way:

- cabinet solidarity is maintained and promoted; and

- cabinet maintains a united front to the national legislature (and the public).

By the same token, coherent and stable government is maintained.

This coherence has the effect of barring public access to the content of cabinet deliberations, which is the primary subject matter of the convention of cabinet secrecy. At the same time, it also precludes any individual member from escaping collective accountability by relying on the content of such deliberations to show that he/she has expressed disagreement with the cabinet decision in question (in this regard, see Carpenter Introduction to South African constitutional law (1987) 183; 
Murray \& Stacey 'The President and the national executive' in Woolman et al (eds) Constitutional Law of South Africa (2014) 32-35).

Under the influence of the Westminster-based constitutional order, and premised on the principle of collective cabinet accountability, cabinet secrecy was practised in South Africa under all constitutions before the constitutional transition in 1994 (Carpenter Introduction to South African constitutional law (1987) 183). Although South Africa, since 1994, has expressly departed from the Westminster system, section 92(2) of the Constitution specifically retained the principle of collective cabinet accountability and provides that '[m]embers of the Cabinet are accountable collectively and individually to Parliament for the exercise of their powers and the performance of their functions'.

Collective accountability implies cabinet confidentiality (secrecy). As long as the cloak of secrecy over the internal workings of cabinet remains intact, cabinet as a whole can be held accountable. An individual member cannot escape accountability by referring to internal discussion and debates of cabinet in which he/she distanced himself/herself from a cabinet decision. Therefore, cabinet secrecy secures, once a decision has been taken, that it is the decision of cabinet as a whole, thus rendering it collectively accountable.

The need for cabinet secrecy, by implication, was also recognised by the Constitutional Court in President of the RSA v SARFU (1999 (10) BCLR 1059 (CC) par 243 (1159C-D)) where the court acknowledged the need for what it described as the protection of robust and uninhibited debate of sensitive and important policy matters in cabinet.

\section{Comparative Jurisdictions}

Since collective cabinet accountability (and the accompanying convention of cabinet secrecy) originated in England, from where it was adopted by other Westminster-based jurisdictions, it is instructive to consider the English position as well as the practice followed in other common law jurisdictions in regard to the convention of cabinet secrecy. The crisp questions in this regard are the following:

- What does the legal position regarding cabinet secrecy in these jurisdictions entail?

- To what extent are the principles of South African law in this regard similar to or different from those in the other jurisdictions?

- Should there be room for the convention of cabinet secrecy in South African constitutional law, and if so, to what extent?

In step with the long-standing practice of South African courts, section 39(1)(c) of the Constitution provides, when interpreting the Bill of Rights, that a court, tribunal or forum may consider foreign law. It stands to reason that such foreign law needs to be comparable to South African law. It is submitted, for present purposes, that the court may take judicial notice that the comparable law in this scenario would be the law of any 
constitutional jurisdiction in which there is a cabinet system similar to the South African system:

- Cabinet takes collective responsibility;

- Ministers are members of the national legislature; and

- The head of the national government is elected from the ranks of the members of Parliament.

The most comparable examples, therefore, are those found in the jurisdictions of the UK, Canada, Australia, India and Kenya which are concisely discussed below.

The sources governing the question of cabinet secrecy and access to cabinet information in these various jurisdictions might be one or more of the following:

(a) common law;

(b) constitutional provisions, more in particular -

(i) provisions that relate to the principle of collective cabinet accountability (or cabinet responsibility or solidarity as it is also called); and cabinet secrecy and/or accessibility to cabinet information; and

(ii) provisions that relate to the constitutional right to information;

(c) specific legislation, more specifically legislation relating to the right of access to information held by any public body.

\section{England}

England is the cradle of the doctrine of cabinet secrecy. In terms of the convention of cabinet secrecy, cabinet is entitled to withhold all cabinet deliberations and, arguably, also (in some cases) cabinet decisions from the public. The convention of cabinet secrecy is premised on the principle of collective cabinet accountability/responsibility, that is, on cabinet solidarity which requires collective ministerial responsibility to the legislature (and the public) and, thus, enables cabinet to maintain a united front and the stability of government and allows ministers to speak frankly and openly in cabinet knowing that their views would not be made public and thus cause embarrassment to government.

The most recent expression of the convention in England is encapsulated in paragraph 2.1 of the Ministerial Code published in May 2010 (available from https://www.gov.uk/government/uploads/system/ uploads/attachment_data/file/61402/ministerial-code-may-2010.pdf (accessed 2015-01-20)) which reads as follows:

The principle of collective responsibility, save where it is explicitly set aside, requires that Ministers should be able to express their views frankly in the expectation that they can argue freely in private while maintaining a united front when decisions have been reached. This in turn requires that the privacy of opinions expressed in Cabinet and Ministerial Committees, including in correspondence, should be maintained. 
Also relevant is the first part of paragraph 2.3 which states that the 'internal process through which a decision has been made, or the level of Committee by which it was taken should not be disclosed'.

It is clear from these provisions that the convention is applicable to the expression of opinions that eventually give rise to decisions, that is, to cabinet proceedings prior to actual decisions and not to actual decisions, that is, decisions that have already been taken. The correct view, so it seems, should therefore be, even though cabinet decisions may be withheld from the public, that such a refusal must be justified on the basis of considerations other than cabinet secrecy and not on cabinet secrecy per se.

Moreover, following the leading judgment of Attorney-General $v$ Jonathan Cape Ltd ([1976] QB 752; [1976] 3 All ER 484; as reflected, amongst others, in Turpin British government and the constitution - Texts, cases and materials (2005) 105-110) it should be clear that the convention of cabinet secrecy does not allow complete confidentiality of all cabinet information. Firstly, the views of individual ministers expressed prior to a decision are covered but not necessarily permanently. Such views, depending on the circumstances, may be disclosed after a period of time, more specifically when such disclosure would no longer prejudice the maintenance of joint cabinet responsibility. Secondly, the question whether or not cabinet information may be disclosed is subject to judicial review. Thirdly, even information that needs to be kept secret need not be kept secret permanently. Secrecy is subject to different time limits, depending on the nature of the information and the possible impact that disclosure might have (Turpin British government and the constitution Texts, cases and materials (2005) 105-110). Some information is required to be kept secret only for a very short period. In the final analysis there cannot be a single rule. Public interest will require that some information be kept secret for varying periods; in other cases public interest will dictate that cabinet information be made public.

The most significant aspect of the current position on cabinet secrecy in England is that blanket secrecy is not countenanced. Cabinet cannot refuse disclosure solely on account of the fact that it is cabinet information. It must justify the refusal on account of considerations pertinent to the information in question and show that the public interest dictates its non-disclosure. If it fails to do so, the information is not covered by the convention of cabinet secrecy and qualifies for public disclosure.

It is instructive that cabinet secrecy has been diluted in England despite the absence of a broad right of access to information similar to that of section 32(1)(a) of the South African Constitution. The English Human Rights Act of 1998, which incorporates the rights outlined in the European Convention on Human Rights and Individual Freedoms (1950) into English law, does not provide for a right of access to information. Taking into account that the South African Constitution does 
acknowledge this right, it may convincingly be argued that the public in South Africa has a stronger entitlement to cabinet information than the public in England.

\section{Canada}

The convention of cabinet secrecy in terms of the principle of collective cabinet accountability was inherited from the English constitutional tradition and is part of the common law of Canada. However, the Canadian Charter of Rights (ch 1 of the Constitution of Canada, 1982) does not include a right of access to information held by the state.

The Canadian Privacy Act, which came into force in 1983, affirms the principle of cabinet secrecy. The Act, which provides in section 12 for a general right of access to information, is, under section 70(1), not applicable to:

(1) confidences of the Queen's Privy Council for Canada (Cabinet), including, without restricting the generality of the foregoing, any information contained in

(a) memoranda the purpose of which is to present proposals or recommendations to Council;

(b) discussion papers the purpose of which is to present background explanations, analyses of problems or policy options to Council for consideration by Council in making decisions;

(c) agenda of Council or records recording deliberations or decisions of Council;

(d) records used for or reflecting communications or discussions between ministers of the Crown on matters relating to the making of government decisions or the formulation of government policy;

(e) records the purpose of which is to brief ministers of the Crown in relation to matters that are before, or are proposed to be brought before Council or that are the subject of communications or discussions referred to in paragraph $(\mathrm{d})$; and

(f) draft legislation.

(2) For the purposes of subsection (1), "Council” means the Queen's Privy Council for Canada, committees of the Queen's Privy Council for Canada, Cabinet and committees of Cabinet.

(3) Subsection (1) does not apply to-

(a) confidences of the Queen's Privy Council for Canada that have been in existence for more than twenty years; or

(b) discussion papers described in paragraph (1)(b)

(i) if the decisions to which the discussion papers relate have been made public, or

(ii) where the decisions have not been made public, if four years have passed since the decisions were made.

It is instructive that all the exclusions listed in this provision relate to matters still under consideration and not to cabinet decisions already 
taken. It, therefore, reinforces the notion that to the extent that there is room for cabinet secrecy, such secrecy pertains primarily to deliberations and not to decisions already taken.

\section{Australia}

Australia has inherited the principle of cabinet secrecy and it is part of the constitutional law of that country. The seventh edition of the Australian cabinet handbook published by the department of the prime minister and cabinet (available from https://www.dpmc.gov.au/sites/ default/files/publications/Cabinet_Handbook.pdf (accessed 2015-01-20)) endorsed the principle of collective cabinet accountability (Cabinet solidarity), thus providing in paragraph 16 that:

Cabinet collective responsibility is most obviously expressed in the principle of Cabinet solidarity. In governments using the Westminster system, members of the Cabinet must publicly support all government decisions made in Cabinet, even if they do not agree with them. Cabinet ministers cannot dissociate themselves from, or repudiate the decisions of their Cabinet colleagues unless they resign from the Cabinet. It is the Prime Minister's role as Chair of the Cabinet, where necessary, to enforce Cabinet solidarity.

Thereafter, under the heading Operational Principles, it endorses and explains the convention of cabinet secrecy, stating as follows in paragraph 20 to 23:

Confidentiality

20. The principle of collective responsibility requires that ministers should be able to express their views frankly in Cabinet meetings in the expectation that they can argue freely in private while maintaining a united front in public when decisions have been reached. This, in turn, requires that opinions expressed in the Cabinet and Cabinet committees, including in documents and any correspondence, are treated as confidential.

21. All attendees are responsible for ensuring that discussions at Cabinet and Cabinet committee meetings remain confidential. Ministers and officials should not disclose proposals likely to be considered at forthcoming meetings outside Cabinet-approved consultation procedures. Nor should they disclose the nature or content of the discussions or the views of individual ministers or officials expressed at the meeting itself. The detail of discussion at Cabinet and Cabinet committee meetings is not recorded in the Cabinet minutes.

22. The vital importance of confidentiality in relation to the deliberations of Cabinet is recognised in legislation and under the common law. The Freedom of Information Act 1982, for example, recognises the special nature of Cabinet deliberations in the exemption it provides for certain Cabinet documents from disclosure ... Cabinet confidentiality is also a well-established ground for not producing documents or information on a public interest immunity basis to courts, royal commissions or legislature.

23. Where a document is being prepared for Cabinet's consideration, care should be taken to expressly state in the body of the document that it is intended that it be considered by Cabinet. This will remove any possible doubt as to the purpose of the document. It is not sufficient to simply 
mark the document as 'Cabinet-in-Confidence', although this practice should be followed for all Cabinet and Cabinet-related documents.

Australia does not have a Bill of Rights and therefore no constitutional right to information.

The doctrine of cabinet secrecy is, in part, affirmed and demarcated by a number of legislative provisions. Section 34 of Australia's Freedom of Information Act 3 of 1982 as amended specifically applies to cabinet documents. It provides that a document is an 'exempt document' (and therefore not accessible to the public) if:

(a) both of the following are satisfied:

(i) it has been submitted to the Cabinet for its consideration, or is or was proposed by a Minister to be so submitted;

(ii) it was brought into existence for the dominant purpose of submission for consideration by the Cabinet; or

(b) it is an official record of the Cabinet; or

(c) it was brought into existence for the dominant purpose of briefing a Minister on a document to which paragraph (a) applies; or

(d) it is a draft of a document to which paragraph (a), (b) or (c) applies.

(2) A document is an exempt document to the extent that it is a copy or part of, or contains an extract from, a document to which subsection (1) applies.

(3) A document is an exempt document to the extent that it contains information the disclosure of which would reveal a Cabinet deliberation or decision, unless the existence of the deliberation or decision has been officially disclosed.

\section{Exceptions}

(5) A document by which a decision of the Cabinet is officially published is not an exempt document.

(6) Information in a document to which subsection (1), (2) or (3) applies is not exempt matter because of this section if the information consists of purely factual material, unless:

(a) the disclosure of the information would reveal a Cabinet deliberation or decision; and

(b) the existence of the deliberation or decision has not been officially disclosed.

In terms of section 36 of the Australian Administrative Appeals Tribunal Act 91 of 1975 as amended, the Attorney-General may issue a so-called public interest certificate in terms of which information may be withheld in the public interest. The provision reads:

(1) If the Attorney-General certifies, by writing signed by him or her, that the disclosure of information concerning a specified matter, or the disclosure of any matter contained in a document, would be contrary to the public interest: 
(a) by reason that it would prejudice the security, defence or international relations of Australia;

(b) by reason that it would involve the disclosure of deliberations or decisions of the Cabinet or of a Committee of the Cabinet; or

(c) for any other reason specified in the certificate that could form the basis for a claim by the Crown in right of the Commonwealth in a judicial proceeding that the information or the matter contained in the document should not be disclosed; the following provisions of this section have effect.

Section 14(1)(b) of the Australian Administrative Decisions (Judicial Review) Act 59 of 1977 as amended, provides for a similar certificate procedure. It provides:

14 Certification by Attorney-General concerning the disclosure of information

(1) If the Attorney-General certifies, by writing signed by him or her, that the disclosure of information concerning a specified matter would be contrary to the public interest:

(b) by reason that it would involve the disclosure of deliberations or decisions of the Cabinet or of a Committee of the Cabinet.

It is clear that Australian law does not acknowledge blanket cabinet secrecy; that the refusal to withhold information is subject to judicial review; and that cabinet secrecy pertains essentially to deliberations prior to the actual taking of decisions.

It is important to underscore that Australia, like England, does not acknowledge a broad right of access to information similar to that of section 32(1)(a) of the South African Constitution. Taking into account that the South African Constitution does acknowledge this right, there is a compelling argument that South African courts should allow for broader public access to cabinet information than is the case in Australia.

\section{Kenya}

As a recently adopted African constitution with a Westminster-based constitutional order with a cabinet system similar to that of South Africa, and a detailed Bill of Rights, the legal position in Kenya is particularly relevant and instructive from a comparative point of view. The Constitution of Kenya of 2010 provides for a general right to information in section 35, subject to a limitation clause in section 24 . The relevant provisions of section 35(1) and (3) read as follows:

(1) Every citizen has the right of access to -

(a) information held by the State; and

(b) information held by another person and required for the exercise or protection of any right or fundamental freedom.

(3) The State shall publish and publicise any important information affecting the nation. 
As to the national executive, section 129(2) of the Constitution provides as follows:

(2) Executive authority shall be exercised in a manner compatible with the principle of service to the people of Kenya, and for their wellbeing and benefit.

There is no trace in the Kenyan Constitution of collective responsibility, nor of the principle of cabinet secrecy. On the contrary, the Constitution specifically provides for decisions of cabinet to be recorded and conveyed to the public. Section 154(2)(c) provides that the '[s]ecretary to the Cabinet shall ... convey the decisions of the Cabinet to the appropriate persons or authorities'.

\section{India}

The Indian Constitution is Westminster-premised and adheres to the principle of collective cabinet accountability. The list of fundamental rights in the Indian Constitution does not include a right of access to information.

The Indian Right to Information Act 22 of 2005 provides for a general right of access to information but subject to a number of exceptions. One of these exceptions deals with information related to the deliberations of cabinet. The relevant provision (s 8(1)(i)) provides as follows:

(1) Notwithstanding anything contained in this Act, there shall be no obligation to give any citizen -

(i) cabinet papers including records of deliberations of the Council of Ministers, Secretaries and other officers:

Provided that the decisions of Council of Ministers, the reasons thereof, and the material on the basis of which the decisions were taken shall be made public after the decision has been taken, and the matter is complete, or over:

Provided further that those matters which come under the exemptions specified in this section shall not be disclosed.

It should be underscored that cabinet secrecy is applicable only to deliberations and not to actual decisions. Moreover, once decisions are taken, the decisions, as well as the motivations (reasons) for such decisions, must be made public.

\section{Discussion}

It is submitted that the exposition above supports a conclusion that the withholding of information of cabinet decisions and deliberations constitutes a prima facie infringement of section 32(1)(a) of the South African Constitution. In terms of this section, everyone has the right of access to information held by the state. Consequently, should the state withhold such information, it bears the burden of proving that the refusal to furnish the information occurred in circumstances which constituted a legitimate limitation under section 36 of the Constitution. Section 36 
provides for two forms of limitation: extra-constitutional limitation and intra-constitutional limitation under section 36(1) and 36(2) respectively.

Extra-constitutional limitation is a well-known form of limitation, having on numerous occasions been dealt with by South African courts. In this scenario, the limitation (by virtue of which the infringement is rendered valid) of the constitutional right originates from law outside the Constitution. Section 36(1) requires that the respondent shows:

(a) that the limitation resulted from law of general application;

and

(b) if so, that the limitation is reasonable and justifiable in an open and democratic society based on human dignity, equality and freedom, taking into account the considerations further mentioned in that subsection.

To meet the second requirement, a proportionality analysis must be carried out. This requires a court to balance the considerations justifying the limitation against the considerations militating against limitation. If the former outweigh the latter, then the infringement would be constitutional but if the latter outweigh the former, it would be unconstitutional. This has been confirmed by South African courts on many occasions starting with Sv Makwanyane (1995 (3) SA 391 (CC); see parr 96-104 \& 110-144).

Intra-constitutional limitation is provided for in section 36(2). In the case of such limitation, the limitation originates from inside the Constitution, that is, it is provided for in the text of the Constitution itself. This form of limitation featured in AZAPO $v$ President of the RSA (1996 (8) BCLR 1015 (CC)).

Arguments in support of the justification to withhold information could be based on either of these forms of limitation. The structure of these arguments will now be set out.

\section{The Argument Based on Section 36(1)}

If the state refuses to disclose cabinet information, it will first have to show that the decision to withhold the information is based on a law of general application. Law includes any rule of law regardless of the nature of the law in question, that is, regardless as to whether it is statutory, common or customary law. Therefore, it obviously does not include a decision or practice which is not authorised by law (August $v$ Electoral Commission 1999 (4) BCLR 363 (CC)). In the present case, it may be contended that the law in question is the common-law convention of cabinet secrecy, inherited from the English Westminster constitutional order which is still in force in present-day South African constitutional law, and that the state, therefore, could legitimately refuse to provide access to cabinet information. The argument may run as follows: South Africa, under the present Constitution, has a cabinet system essentially similar to that of England and the other jurisdictions dealt with above. In 
this system the principle applies that all members of cabinet take collective responsibility for the policy adopted by cabinet. No individual member may distance himself/herself from a decision on the grounds that he/she is not in agreement with the decision and has voiced his/her disagreement during cabinet deliberations. Were it not for this convention, cabinet would not have been able to maintain a united front to the national legislature (and the public). On these premises it would be required that public access to the content of the deliberations and decisions be barred and cabinet secrecy thus be maintained.

This argument is supported by section 92(2) of the Constitution which essentially absorbed the principle of collective cabinet accountability by providing that members of the Cabinet are accountable collectively and individually to Parliament for the exercise of their powers and the performance of their functions. Cabinet secrecy is clearly implied in this principle (this contention is supported by the dictum referred to by the Constitutional Court in President of the RSA $v$ SARFU 1999 (10) BCLR 1,059 (CC) par 243 (see par 2 above)).

The merits of the argument supporting refusal of public access to cabinet information are now dealt with. First, it may readily be conceded that the convention of cabinet secrecy known to Westminster-based constitutional dispensations is also part of present-day South African constitutional law. However, the scope of the materials protected by the convention of cabinet secrecy is, or rather should be, restricted. It should not cover all proceedings of cabinet. More particularly, information that could clearly disclose individual views expressed by members of cabinet that could reveal differences between members of the cabinet (particularly if the President and/or the Deputy President are involved), should not be disclosed. In consequence, deliberations of cabinet as well as voting patterns, if any, as well as all other information that could reveal internal divisions in cabinet, should be covered by the convention of cabinet secrecy.

Such deliberations and related information that could reveal internal differences must clearly be distinguished from cabinet decisions, especially decisions on policy, that have an impact on the general public. Such decisions should not be subjected to cabinet secrecy and should, therefore, be available to the public in terms of section 32(1)(a), unless the respondent can offer a compelling justification, other than cabinet secrecy, for refusing disclosure of information. This submission is supported by the comparative foreign law dealt with above as well as South Africa's distinctive legal regime.

As far as the comparative position is concerned, it could be argued that the Kenyan position is the most comparable and therefore emphatically instructive in order to conclude upon the South African position. The Kenyan Constitution, like that of South Africa, is a recently passed African constitution. For two reasons it is essentially similar to that of South Africa. First, section 129(2) of the Kenyan Constitution provides for 
a broad principle of executive conduct similar to the foundational values outlined in section 1 of the South African Constitution. Section 129(2) of the Kenyan Constitution provides as follows:

(2) Executive authority shall be exercised in a manner compatible with the principle of service to the people of Kenya, and for their wellbeing and benefit.

Second, the Kenyan Constitution, like the South African Constitution, has a Bill of Rights with a full set of constitutional rights, including the right of access to information provided for in section 35(1) of the Kenyan Constitution which provides that every citizen has the right of access to information held by the state. Additionally, section 35(3) burdens the state with the duty to publish any important information affecting the nation. Section 154(2) of the Kenyan Constitution reinforces this right and the corresponding duty by enjoining the secretary to the cabinet to 'convey the decisions of the Cabinet to the appropriate persons or authorities'.

Indian law, on the right of access to cabinet information, is premised on a distinction between the deliberation stage (i.e. the stage during which the decision is still under consideration) and actual decisions. The latter must be made available to the public whilst the former may be kept confidential. This is made clear by the Indian Right to Information Act 22 of 2005 which provides for a general right of access to information but which is subject to a number of exceptions provided for in section 8(1)(i) of the Act - including information that relates to the deliberations of cabinet, as quoted in paragraph 35 above. Therefore, once a decision is taken and the matter is complete, or over as it is stated in the section, it must be made public.

As mentioned in the discussion of the English position, English constitutional law does not recognise a blanket cabinet secrecy and now provides for a broad public access to cabinet information. This is so in spite of the fact that, unlike the position in South Africa, a broad constitutional right of access to information is not recognised in English law. The same holds true for the position in Australia and Canada. To the extent that there possibly might be a residual tendency in English law, and in the law of any of the jurisdictions discussed here (notably those of Australia and Canada), to withhold cabinet information, such tendency cannot, for the following four reasons, qualify as convincing comparative authority in support of withholding cabinet information from the public.

First, the English constitutional order (and that of any of the others discussed here) does not have the same explicitly defined normative value basis as that provided for in section 1 of the South African Constitution which includes the value of 'human dignity, the achievement of equality and the advancement of human rights and freedoms ... to ensure accountability, responsiveness and openness'. 
Second, English law (and that of the other states discussed here) does not acknowledge a general right of access to information held by the state in the way section 32(1)(a) of the South African Constitution does. In South Africa the right of access to information, therefore, is recognised in much bolder terms than in England, Australia and Canada. In consequence, the law of the latter three states provides insufficient support for the view that South African law should correspond with, or be in keeping with, that of those states in so far as the denial of access of information to state information is concerned.

Third, it should be underscored that the convention of cabinet secrecy is not an autonomous convention but rather one which could be described as an accessory convention. It does not exist for its own sake. Its raison d'être is collective cabinet accountability and coherent government. Hence, there should be room for cabinet secrecy only to the extent that it is indispensable for collective cabinet accountability and coherent government. Conversely, if collective cabinet accountability and coherent government are achievable without cabinet secrecy, there should be no room for secrecy. For that reason it could readily be accepted that deliberations that preceded actual cabinet decisions generally (though not necessarily always) should be kept secret. By the same token, matters still under consideration, that is, where decisions are still to be made, should generally also qualify for cabinet confidentiality. However, once a decision of cabinet is taken the reason for cabinet secrecy falls away. Decisions which have already been reached represent the united front of cabinet for which cabinet, as a collective, is accountable. The public announcement of a cabinet decision should therefore be regarded as the embodiment of the principle of collective cabinet accountability. By contrast, the refusal to make public such decisions, that is, to deny public access to such decisions, defeats the principle of collective cabinet accountability. Without public knowledge of such decisions, cabinet cannot be held accountable. The merits of the decision cannot be appreciated and it is impossible to establish whether cabinet has in fact acted in accordance with its own decisions.

Fourth, there is a certain category of cabinet decisions the very purpose of which is that they should be made public. Their very raison d'etre is that the public should have access to them. Decisions relating to the rules or guidelines applied by the President, Deputy President and members of cabinet relating to matters such as travel benefits, travel arrangement and private holidays should fall within this category. These rules are to be adhered to as they are essentially an instrument in terms of which public accountability could be given effect to. Without public knowledge of the rules in relation to this question, public accountability would be rendered impossible which, at the same time, opens the door to the uncontrolled misuse of public funds. Collective accountability of cabinet and individual accountability of cabinet members as envisaged in section 92(2) of the South African Constitution do not detract from this conclusion. On the contrary, it requires such information to be made 
public. If not, the very principle of public accountability falls by the wayside.

\section{The Argument Based on Section 36(2)}

Section 36(2) of the Constitution provides that "[e]xcept as provided in subsection (1) or in any other provision of the Constitution, no law may limit any right entrenched in the Bill of Rights' (own emphasis).

In essence, section 36(2) provides that a provision elsewhere in the Constitution (but outside the Bill of Rights) may justifiably limit any of the constitutional rights of Chapter 2. Such intra-constitutional limitation (intra-constitutional because it originates from within the text of the Constitution) is not required to meet the requirements for limitation set out in section 36(1). Such limitations are justified solely because they are part of the Constitution (AZAPO v President of the RSA 1996 (8) BCLR $1015(\mathrm{CC})$ ).

In the premises it may be argued that the principle of collective cabinet accountability, which is expressly enacted in section 92(2) of the Constitution, entails that the convention of cabinet secrecy is a logical concomitant of collective cabinet accountability. However, it is the opinion of this author that there is limited merit in this argument because, although it might be conceded that cabinet secrecy is implied by collective cabinet accountability, there is no basis for arguing that such secrecy is a blanket and unqualified one. Cabinet secrecy is in fact qualified and, in each case, must be justified by any party insisting on such secrecy with reference to the considerations applicable to each case. This should be clear from the foreign law which has been outlined in the discussion above, as well as from the relevant South African constitutional provisions, notably section 1 and section 32(1)(a) that clearly do not countenance blanket secrecy.

\section{Conclusion}

Section 12(a) of PAIA should not be viewed as a limitation of the right of access to information held by cabinet. The effect of the provision is rather that the legal regime created by PAIA is not applicable to cabinet information. The applicable law that governs the question of access to cabinet information is section 32(1)(a) which has to be read with section 92(2) of the Constitution and with reference to the development of the common law principles surrounding cabinet secrecy in comparable jurisdictions. Such analysis brings to light that cabinet secrecy has been restricted and that the scope of public access to information held by cabinet should be interpreted generously, especially when it is clear that some public interests are obviously at stake. In such circumstances the broadly defined right of access to information and the constitutional value of accountability, responsiveness and openness, as outlined, leave but very limited scope for justifiably refusing cabinet information. This 
conclusion is strongly reinforced by the law of comparable jurisdictions as discussed above.

K MALAN

University of Pretoria 